\title{
ABDÔMEN AGUDO
}

\author{
ACUTE ABDOMEN
}

Omar Feres ${ }^{1}$, Rogério Serafim Parra ${ }^{2}$

${ }^{1}$ Docente, ${ }^{2}$ Médico Residente. Divisão de Coloproctologia do Departamento de Cirurgia e Anatomia da FMRP-USP.

Correspondência: Omar Feres. Divisão de Coloproctologia do Departamento de Cirurgia e Anatomia da FMRP-USP. Av. Bandeirantes, 3900. CEP: 14048-900 - Ribeirão Preto /SP. (email: feresomar@ netsite.com.br)

Feres O, Parra RS. Abdômen agudo. Medicina (Ribeirão Preto) 2008; 41 (4): 430-6.

RESUMO: O abdome agudo configura um quadro clínico de dor dos mais importantes e freqüentes na prática clínica. Pela sua gravidade necessita de condutas diagnósticas e terapeuticas urgentes. Pode ser decorrente de inúmeras doenças. O texto discorre sobre diferentes etiopatogenias e as bases do quadro clínico, essenciais para o diagnóstico e tratamento.

Descritores: Abdome Agudo.

\section{1- DEFINIÇÃO}

Quadro clínico abdominal caracterizado por dor, de início súbito ou de evolução progressiva, que necessita de definição diagnóstica e de conduta terapêutica imediata. Muitas doenças, algumas das quais não necessitam de tratamento cirúrgico, causam dor abdominal, de modo que a avaliação de pacientes com dor abdominal deve ser metódica e cuidadosa. Como existe, com frequiência, um distúrbio intra-abdominal progressivo, o retardo do diagnóstico e do tratamento afetam o prognóstico.

A conduta para o paciente com abdômen agudo deve ser ordenada e completa. $\mathrm{O}$ tratamento adequado de pacientes com dor abdominal aguda necessita de uma decisão em tempo hábil quanto à necessidade de cirurgia. Esta decisão exige avaliação da história e do exame físico, exames laboratoriais e exames de imagem. A anamnese e o exame físico costumam sugerir as prováveis etiologias e orientar a escolha dos exames diagnósticos iniciais. O médico deve decidir se há exigência de observação em regime hospitalar, se são necessários exames adicionais ou se já existe indicação cirúrgica imediata.
Todos os médicos e estudantes de medicina devem estar familiarizados com as causas mais comuns de abdômen agudo (Quadro 1). Além disto, devem reconhecer os padrões de doença específicos para a região e o local em que atuam.

Quadro 1: Causas comuns de abdômen agudo

- Distúrbios do trato gastrintestinal

Dor abdominal inespecífica*

Apendicite aguda*

Obstrução intestinal*

Ulcera péptica perfurada*

Hérnia encarcerada

Perfuração intestinal

Diverticulite aguda*

Diverticulite de Meckel

Síndrome de Boerhaave

Distúrbios intestinais inflamatórios

Gastrenterite aguda e gastrite aguda

Adenite mesentética

Infecções parasitárias

- Distúrbios do fígado, baço e trato biliar

Colecistite aguda*

Colangite aguda

Abscesso hepático íntegro ou roto 
Tumor hepático roto

Rotura espontânea do baço

Infarto e abscesso esplênicos

Cólica biliar

Hepatite aguda

Distúrbios pancreáticos

*Pancreatite aguda, pseudocistos do pâncreas in-

fectados, abscessos pancreáticos

- Distúrbios do trato gênito-urinário

*Cólica renal ou ureteral

Pielonefrite aguda

Cistite aguda

Infarto renal

Orquiepididimite

- Distúrbios ginecológicos

Prenhez ectópica rota

Torção de tumor de ovário

Ruptura de cisto de folículo ovariano

Salpingite aguda*

Dismenorréia

Endometriose, endometrite

- Distúrbios vasculares

Rotura de aneurisma: aorto-ilíaco, hepático, renal, esplênico e outros.

Colite isquêmica aguda

Trombose mesentérica

- Distúrbios peritoneais e retroperitoneais

Abscessos intra-abdominais

Peritonite primária

Hemorragia retroperitoneal

*Condições mais comunsestão marcadas com asterisco.

\section{1- Características gerais}

Em virtude da complexa rede sensorial visceral e parietal dupla que inerva a área abdominal, a dor não é localizada com tanta exatidão quanto nos membros. Felizmente, alguns padrões gerais emergem, fornecendo indícios para o diagnóstico. Diferentemente da dor cutânea, a dor visceral é provocada por distensão, por inflamação ou isquemia, que estimulam os neurônios dos receptores, ou por envolvimento direto dos nervos sensoriais (p.ex., infiltração neoplásica). A dor visceral é mais frequentemente percebida na linha média, por causa do suprimento sensorial bilateral para a medula espinhal. Já a dor parietal gera sensação mais localizada, aguda e nítida. A irritação direta do peritônio parietal somaticamente inervado (principalmente as partes superior e anterior) por pus, bile, urina ou secreção gastrintestinal leva à dor localizada.
A dor abdominal pode ser referida ou se deslocar para sítios diferentes dos órgãos primariamente afetados, indicando sensações cutâneas, percebidas em um local diferente daquele do estímulo primário.

A localização da dor serve apenas como uma orientação para o diagnóstico. As descrições típicas ocorrem em dois terços dos casos.

Os pacientes com abdômen agudo geralmente estão apreensivos e amedrontados quando se apresentam ao médico. A síndrome da dor abdominal aguda pode acometer todas as faixas etárias, de ambos os sexos e todos os grupos sócio-econômicos.

\section{2- Anatomia}

A anatomia evolutiva da cavidade abdominal e de suas vísceras determina a estrutura normal tem relação direta com as manifestações clínicas da maioria das doenças abdominais. Doenças do duodeno proximal (intestino anterior) estimulam os aferentes do tronco celíaco a produzirem dor epigástrica. Estímulos no ceco ou apêndice (intestino médio) ativam nervos aferentes que acompanham a artéria mesentérica superior, provocando dor periumbilical. A doença do cólon distal induz as fibras aferentes da artéria mesentérica inferior a provocarem dor suprapúbica. Estímulos para o diafragma causam dor referida no ombro.

\section{3- Avaliação, diagnóstico e exames comple- mentares}

A dor é o item principal na avaliação de um paciente com suspeita de abdômen agudo. A anamnese deve caracterizar a dor de maneira precisa. A duração da dor, sua localização, como se iniciou e outras características como tipo de dor e evolução podem ajudar no diagnóstico diferencial. A dor visceral causada por distensão, inflamação ou isquemia é difusamente localizada na região mesogástrica. Doenças renais ou ureterais causam dor nos flancos. Sangue ou pus subdiafragmático à esquerda podem gerar dor no ombro esquerdo, doença biliar pode causar dor referida no ombro direito ou dorso. Doenças supradiafragmáticas, como uma pneumonia basal, podem causar dor referida no pescoço ou ombro. Dor abdominal no andar superior do abdômen sugere úlcera péptica, colecistite aguda ou pancreatite. Por outro lado, cisto de ovário, diverticulite e abscessos tubo ovarianos causam dor na porção inferior do abdômen. Geralmente, a obstrução do intestino delgado causa dor no mesogástrio, que, às vezes, é referida no dorso. 
A dor que se move do epigástrio para a região peri-umbilical, até chegar na fossa ilíaca direita, sugere o diagnóstico de apendicite aguda. Outro exemplo de dor migratória é a da úlcera duodenal perfurada. O extravasamento do conteúdo duodenal causa dor epigástrica intensa e localizada. No entanto, se o conteúdo extravasado gravitar pelo corredor parietocólico direito, o paciente pode referir dor na fossa ilíaca direita. Embora a localização da dor possa ser útil principalmente nas fases precoces da evolução de uma doença, pode não ser típica em todos os pacientes e, em fases avançadas, pode se tornar generalizada em virtude de uma peritonite difusa. O sangramento para o peritônio livre também causa dor difusa e quadro de peritonismo (Quadro 2).

Quadro 2: Causas de hemoperitônio

\section{- Gastrintestinais}

Laceração traumática do fígado, baço, pâncreas, mesentério, intestino.

- Ginecológicas

Rotura de prenhez ectópica

Rotura de folículo de Graaf

Rotura de útero

- Vascular

Rotura de aneurisma: aorto-ilíaco, hepático, renal e esplênico.

- Urológica

Rotura de bexiga

- Hematológica

Rotura de baço

A dor abdominal pode-se iniciar repentinamente ou instantaneamente, sem sintomas prévios. O início súbito ou explosivo sugere perfuração de uma víscera para o peritônio livre, como o duodeno ou estômago, ou isquemia intestinal aguda, em virtude de embolia arterial visceral. A dor de caráter progressivo corresponde à apresentação habitual de doenças que comumente produzem abdômen agudo, tais como colecictite aguda, pancreatite aguda e obstrução de delgado proximal. Algumas doenças iniciam-se com desconforto abdominal, vago generalizado, que evolui para dor abdominal em algumas horas. A dor torna-se mais intensa e subsequentemente se localiza. Este grupo de doenças inclui a apendicite aguda, hérnia encarcerada, obstrução de delgado distal, obstrução de cólon, diverticulite e perfuração de víscera bloqueada (Quadro 3).

Quadro 3: Dor abdominal secundária a lesões inflamatórias do sistema digestório

- Estômago

Úlcera péptica perfurada (gástrica ou duodenal)

- Vias biliares

Colecistite aguda litiásica ou alitiásica

- Pâncreas

Pancreatite aguda, recidivante ou crônica

- Intestino delgado

Doença de Crohn

Divertículo de Meckel

- Intestino grosso

Apendicite

Diverticulite

A qualidade, gravidade e periodicidade da dor podem colaborar no diagnóstico. A úlcera duodenal e a apendicite perfurada causam dor constante e aguda. Dor precoce de obstrução de delgado é vaga e profunda. A partir daí, esta dor assume características crescentes e decrescentes, tipo cólica (Quadro 4). Se a obstrução causar infarto intestinal, a dor se tornará prolongada e constante. A dor da obstrução ureteral é extremamente intensa. Dor aguda no abdômen superior, no tórax inferior ou região interescapular sugere dissecção aórtica.

Quadro 4: Dor abdominal secundária a lesões obstrutivas do tubo digestivo

\begin{tabular}{lll}
\hline Jejuno & Íleo & Cólon \\
\hline Doença maligna & Doença maligna & Doença maligna \\
Volvo & Volvo & Volvo de ceco \\
Aderências & Aderências & Volvo de sigmóide \\
Intussuscepção & Intussuscepção & Diverticulite \\
Crohn & Crohn & Colite isquêmica \\
& Actínica & Colite actínica \\
\hline
\end{tabular}


Outros sinais e sintomas podem ocorrem juntamente com a dor abdominal. Com frequiência, os vômitos antecedem a dor na gastrenterite, enquanto na apendicite aguda, a dor abdominal ocorre por algum tempo, antes do surgimento dos vômitos. Freqüentemente ocorrem vômitos nos pacientes com colecistite aguda, pancreatite e obstrução intestinal. A obstrução distal à ampola de Vater provoca vômitos biliosos, enquanto a obstrução proximal à ampola provoca vômitos claros. A diarréia aquosa associada à dor abdominal sugere gastrenterite aguda. A impossibilidade de eliminar gases ou fezes sugere obstrução intestinal mecânica.

É importante colher uma história menstrual cuidadosa em mulheres com dor abdominal. A ovulação pode produzir dor abdominal significativa. Além disto, mulheres com atraso menstrual com dor abdominal podem estar com problemas relacionados a uma gravidez não diagnosticada ou ectópica.

A historia medicamentosa é também importante. Os corticoesteróides predispõem à ulceração gastrintestinal e possibilidade de perfuração, além de induzirem imunossupressão nos pacientes em uso crônico, ofuscando manifestações de doença intra-abdominal aguda. O uso de anticoagulantes orais ou antiagregantes plaquetários podem levar a hemorragias intra-abdominais espontâneas.

O exame físico geralmente fornece importantes informações no diagnóstico diferencial e tratamento de pacientes com dor abdominal aguda. Avaliar o aspecto geral do paciente, biótipo e sinais de dor. Febre baixa geralmente acompanha a diverticulite, apendicite ou colecistite aguda. Febre mais elevada, na maioria das vezes, acompanha a pneumonia, pielonefrite, colangite séptica, e afecções ginecológicas. Aumento da frequiência cardíaca e hipotensão podem significar doença complicada com peritonite. A peritonite causa hipovolemia à medida que o volume plasmático estravasa do espaço intravascular.

Iniciar o exame físico pela inspeção a procura de cicatrizes, hérnias inguinais e escrotais, distensão, massas e defeitos da parede abdominal (Figura 1). A seguir a palpação, etapa fundamental na avaliação do paciente com abdômen agudo. Dor localizada na fossa ilíaca direita, no ponto de McBurney sugere apendicite aguda (Figura 2). Dor no hipocôndrio direito sugere inflamação da vesícula biliar. Diverticulite aguda freqüentemente causa dor na fossa ilíaca esquerda. Dor desproporcional ao exame físico sugere isquemia intestinal e dor difusa sugere peritonite generalizada.

A detecção de aumento do tônus muscular abdominal, durante a palpação é chamada de defesa da parte abdominal. Ela pode ser voluntária ou não, e localizada ou generalizada. A irritação peritonial é um sinal de peritonite. Para sua detecção, o examinador, com a mão, comprime profundamente o abdômen do paciente e a retirada súbita da mão causa aumento agudo da dor. Na colecistite aguda, a palpação da região subcostal direita,durante inspiração profunda, pode provocar dor (sinal de Murphy).

A ausculta de um abdômen silencioso sugere íleo paralítico, enquanto movimentos peristálticos hiperativos ocorrem na gastrenterite aguda. Períodos de silêncio abdominal intercalados com peristalse hiperativa caracterizam a luta contra a obstrução mecânica do intestino delgado.

A percussão abdominal pode revelar dor, sugerindo inflamação (irritação peritoneal). O hipertimpanismo à percussão do abdômen significa distensão gasosa do intestino ou estômago e timpanismo à percussão sobre o fígado sugere ar livre intra-peritonial e perfuração de víscera oca.

Realizar sempre o toque retal nos pacientes com quadro de dor abdominal aguda à procura de sangue, massas ou dor, e em mulheres sempre realizar o exame pélvico bimanual em procura de massas ou sensibilidade uterina ou anexial (Quadro 5). Apêndice pélvico inflamado ou abscesso pélvico podem causar dor ao toque retal ou mesmo toque vaginal.

A investigação laboratorial geralmente inclui hemograma. A inflamação intra-abdominal causa leucocitose, porém esse é um dado inespecífico. A dosagem de amilase e lipase auxilia no diagnóstico de pancreatite aguda. No entanto, outras doenças, tais como úlcera duodenal perfurada e infarto de delgado podem gerar aumento da amilase sérica. $\mathrm{O}$ exame de

Quadro 5: Dor abdominal secundária a lesões ginecológicas

\begin{tabular}{lll}
\hline Ovário & Trompas & Útero \\
\hline Rotura do folículo de Graaf & Prenhez ectópica & Rotura \\
Torção de ovário & Salpingite aguda & Endometrite \\
\hline
\end{tabular}


urina pode auxiliar no diagnóstico de infecção urinária e litíase renal. Mulheres em idade gestacional devem ter a dosagem de gonadotrofina coriônica sérica realizada.

A história e exame físico são passos principais na avaliação dos pacientes com dor abdominal. Os exames de imagem melhoram a eficácia diagnóstica e o tratamento global dos pacientes que se apresentam com dor abdominal aguda. Uma radiografia de abdômen com incidência no diafragma (ortostática) pode detectar pneumoperitônio de até $1 \mathrm{ml}$. Se o paciente não puder ficar sentado, a radiografia pode ser realizada em decúbito lateral esquerdo, e o pneumoperitônio será visível se houver de 5 a $10 \mathrm{ml}$ na cavidade peritoneal. setenta e cinco porcento das úlceras duodenais perfuradas causam pneumoperitônio e as perfurações de estômago e cólon, geralmente, provocam grandes pneumoperitônios (Figura 1).

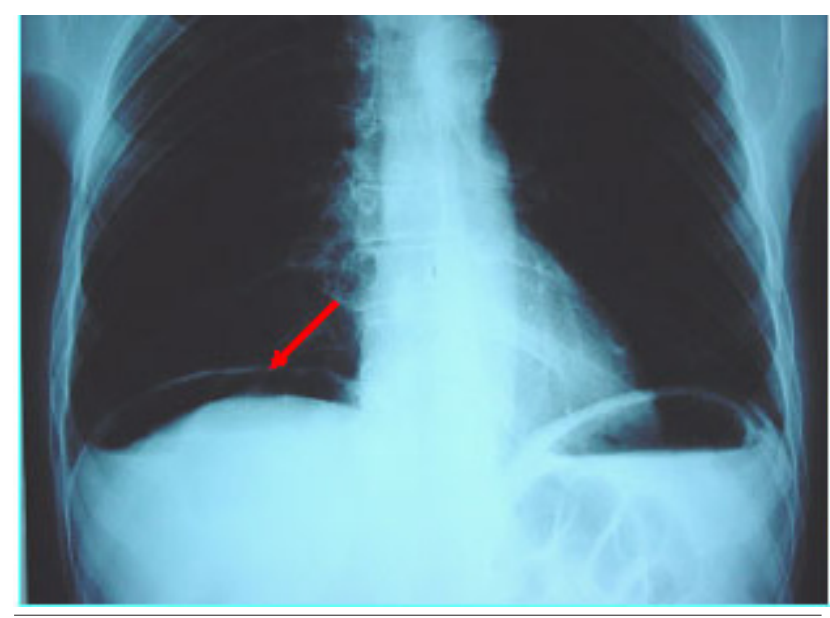

Figura 1: Radiografia de tórax evidenciando pneumoperitôneo com ar entre a cúpula frênica e o fígado à direita e entre a cúpula frênica e o estômago à esquerda.

Dez por cento das colelitíases e 90\% dos cálculos renais são radiopacos e demonstráveis pelo exame radiológico não contrastado de abdômen. Calcificações pancreáticas e vasculares, sugerindo pancreatite crônica e doenças vasculares, respectivamente, são achados radiológicos que auxiliam no diagnóstico. O íleo paralítico pode provocar distensão intestinal com múltiplos níveis hidroaéreos (Figura 2).

A ultrassonografia é de baixo custo, rápida e segura, podendo ser utilizada em mulheres grávidas. É bastante sensível e específica para doenças da vesícula biliar, e também pode ser utilizada para avaliação do baço, rins e sistema coletor, apêndice, útero e anexos. A tomografia de abdômen é capaz de ajudar na avaliação de abscessos intra-abdominais, pâncreas, rins e demais estruturas intra e retro-peritoneais.

\subsection{Tratamento}

As informações obtidas pela história clínica, exame físico, exames laboratoriais e de imagem geralmente permitem um diagnóstico, mas ainda pode permanecer uma incerteza . O cirurgião deve tomar a decisão de operar ou não, baseado nas informações obtidas.

É prudente dividir, baseado no raciocínio clínico, o abdômen agudo em "síndromes": inflamatória, perfurativa, obstrutiva, vascular e hemorrágica.

- Inflamatório: a dor é de inicio insidioso, com agravamento e localização com o tempo. O paciente apresenta sinais sistêmicos, tais como febre e taquicardia. As doenças mais comuns são: apendicite aguda, colecistite aguda, diverticulite aguda, pancreatite, anexite aguda. A apendicite é a causa mais comum de abdômen agudo cirúrgico no mundo. Pode ocorrer em qualquer faixa etária, mas é mais comum em adolescentes e adultos jovens (Figuras 3 e 4 ).

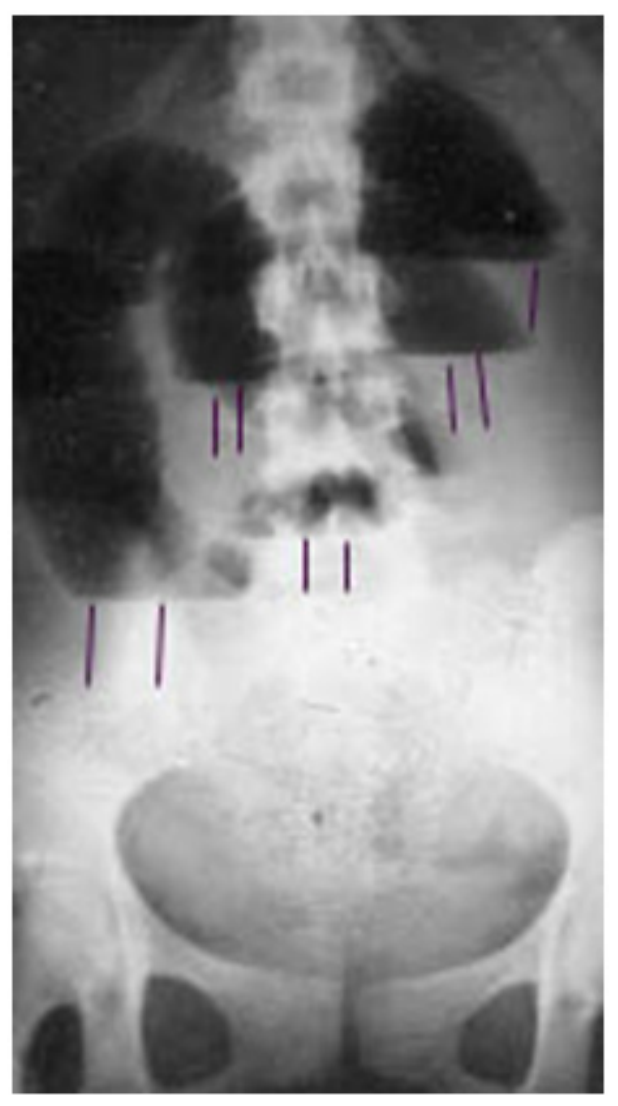

Figura 2: Radiografia não contrastada de abdômen mostrando dilatação de alças de intestino delgado com níveis hidroaéreos. 


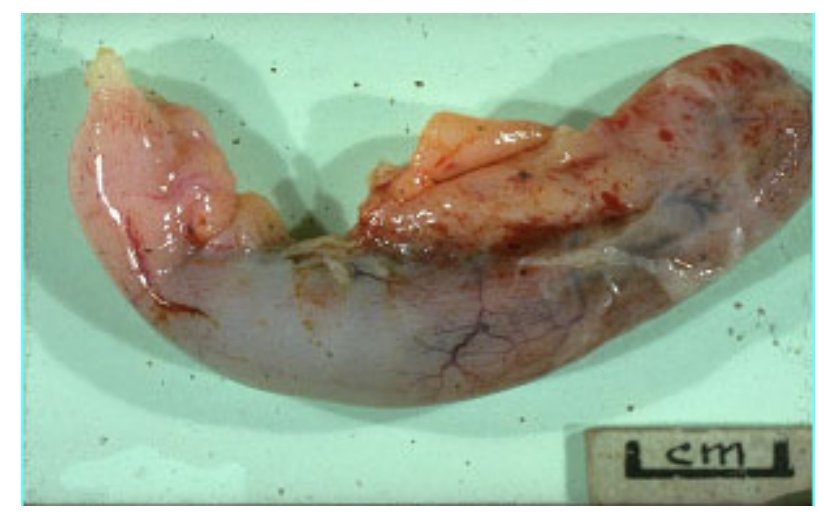

Figura 3: Peça cirúrgica de apendicite aguda. Nota-se edema e hiperemia secundários ao processo inflamatório.

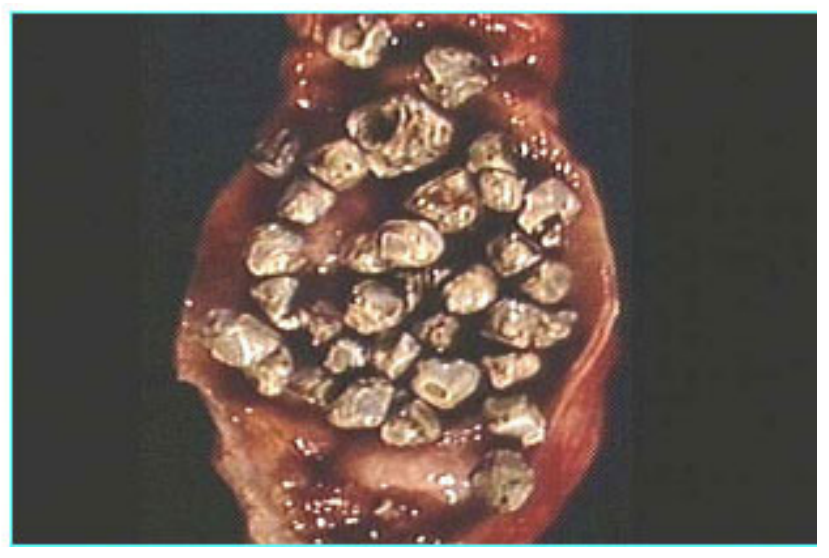

Figura 4: Colecistite aguda. Nota-se parede espessada e inflamada e grande quantidade de cálculos em seu interior.

- Perfurativo: a dor é súbita e intensa, com defesa abdominal e irritação peritoneal. Há derrame do conteúdo de víscera oca no peritônio, geralmente secundário à úlcera gastroduodenal, diverticulite, corpos estranhos e neoplasias (Figura 5).

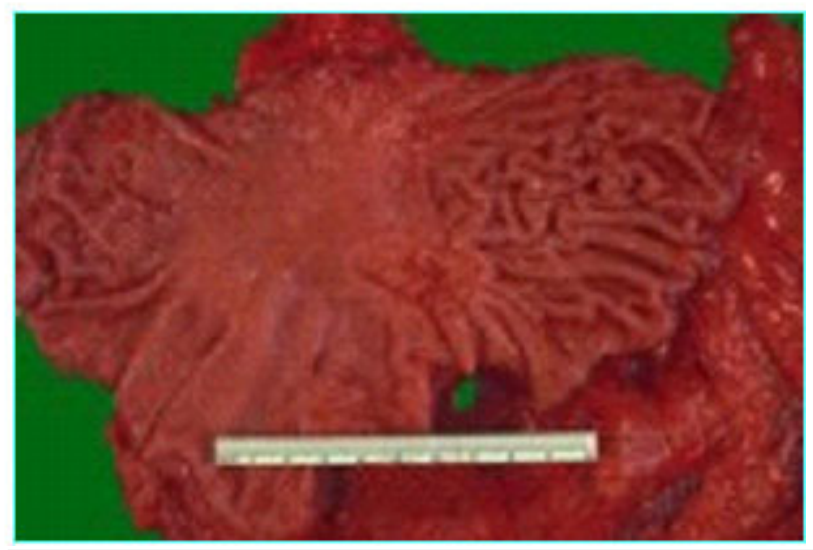

Figura 5: Úlcera pética perfurda.
- Obstrutivo: a dor é em cólica, geralmente periumbilical. Associadamente surgem náuseas, vômitos, distensão abdominal, parada da eliminação de flatos e fezes. Acontece na oclusão mecânica por bridas, hérnias, neoplasias e invaginação (Figura 6).

A

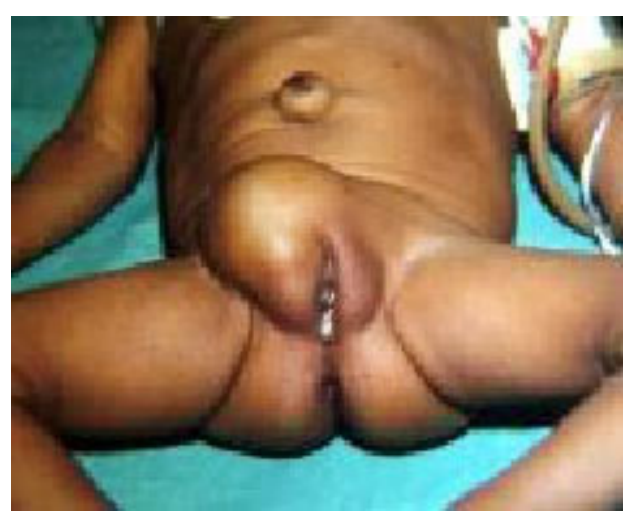

B

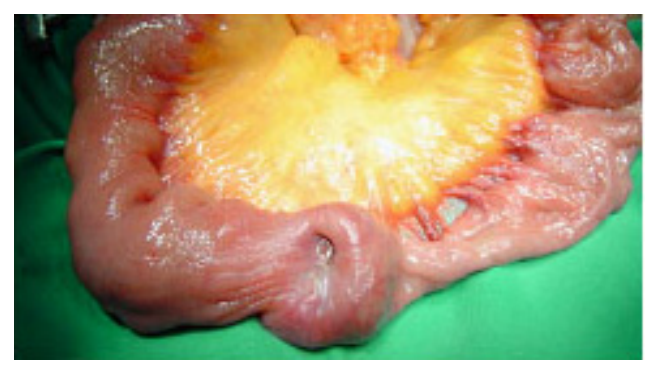

Figura 6: A- Grande hérnia inguinal encarcerada e B- Invaginação intestinal hérnia umbilical

- Vascular: a dor é difusa e mal definida, há desproporção entre a dor e o exame físico e as causas mais comuns são embolia e trombose mesentérica, com isquemia intestinal (Figura 10).

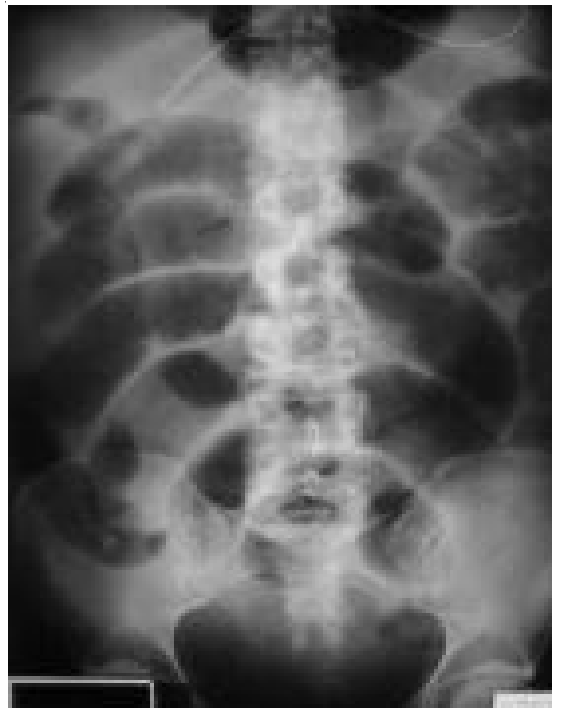

Figura 7: Radiografia de abdômen mostrando dilatação difusa do intestino delgado, secundária à trombose mesentérica. 
- Hemorrágico: a dor é intensa, com rigidez e dor à descompressão; há sinais de hipovolemia, tais como hipotensão, taquicardia, palidez e sudorese. As causas mais comuns são prenhez ectópica rota, ruptura de cistos, ruptura de aneurismas, rotura de baço (quadro 2).

O cirurgião não precisa saber o diagnóstico, mas precisa saber se há ou não necessidade de cirurgia.
Existem causas não-cirúrgicas de dor abdominal (quadro 6).

O cirurgião deve ser capaz de avaliar o paciente e decidir sobre a necessidade de cirurgia. Os antigos cirurgiões experientes diziam: "Não se deve esperar amanhecer para operar um paciente com abdômen agudo".

\section{Quadro 6: Causas não cirúrgicas de dor abdominal.}

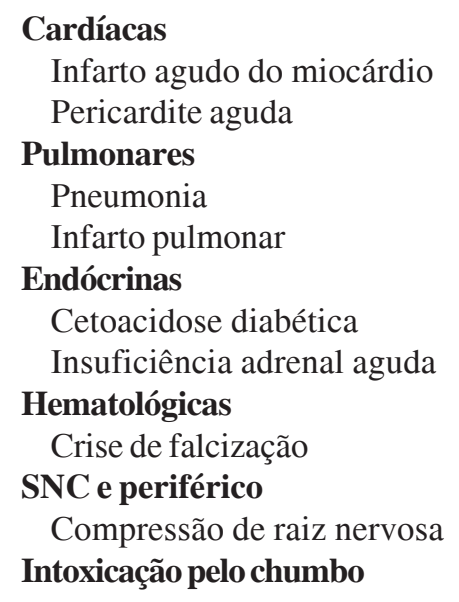

\author{
Gastrintestinais \\ Pancreatite aguda \\ Gastroenterite \\ Hepatite aguda \\ Metabólicas \\ Porfiria aguda \\ Hiperlipidemia \\ Músculo-esqueléticas \\ Hematoma músc. reto abdominal \\ Genitourinárias \\ Pielonefrite \\ Cistite \\ Salpingite aguda
}

Feres O, Parra RS. Acute abdomen. Medicina (Ribeirão Preto) 2008; 41 (4): 430-6.

ABSTRACT: The acute abdomen is one of the major and most frequently occurring syndromes in clinical practice and, since it can be caused by various different diseases, it demands an urgent diagnosis and treatment. The present text expatiates upon the different etiopathogeneses of this syndrome as well as upon its bases, which are crucial for the diagnosis and treatment of an acute abdomen.

key words: Abdomen, Acute.

\section{BIBLIOGRAFIA RECOMENDADA}

1- Rocha PR, Andrade JI, Souza C. Abdômen Agudo. 2a․ ed, Ed.Médica e Científica Ltda, 1993.

2- Batista Neto J. Cirurgia de Urgência. Condutas. Ed. Revinter 1999.

3- Vinhaes Jc. Clínica e terapeutica cirurgicas. Ed. Guanabara Koogan, $2^{\mathrm{a}}$ ed. 2003.

4- Bockus MC. Abdominal pain. In: Berck JE. Bockus Gastroenterology. $4^{\mathrm{a}}$ ed. Philadelphia Saunders, 1985.
5- Jawyer Jl. (ed). Abdome agudo. Clin cir am norte 1988; 68 (2): 243-490.

6- Abrantes WL. Abdome agudo. In: Lopez M. Emergências médicas. 5aㅡ. ed. Rio de Janeiro, Guanabara Koogan, 1909. p. 484-99.

7- Silva AL. Cirurgia de urgência. Editora Médice, 2ª ed. 1994.

Recebido para publicação em 20/08/2008

Aprovado para publicação em 23/10/2008 